\title{
Performance measurement for planning and control in SMEs
}

\author{
M. Hudson ${ }^{1)}$, J. P. Bennett ${ }^{1)}$, A. Smart ${ }^{2)}$, M. Bourne ${ }^{3)}$, \\ ${ }^{1)}$ University of Plymouth, Drake Circus, Plymouth, UK \\ Tel: +44 1752233524 \\ Fax: +441752233505 \\ e-mail:mhudson@plymouth.ac.uk \\ ${ }^{2)}$ University of Exeter, Streatham Court, Rennes Drive, \\ Exeter, $U K$ \\ Tel: +44 1392263213 \\ Fax: +441392263242 \\ e-mail:P.A.Smart@exeter.ac.uk \\ ${ }^{3)}$ University of Cambridge, Manufacturing Engineering Group, \\ Mill Lane, Cambridge, UK \\ Tel: +44 1223337085 \\ Fax: +441223338076 \\ e-mail:mcsb@eng.cam.ac.uk
}

\begin{abstract}
This paper explores the concept of strategic performance measurement in SMEs. To provide some depth and breadth for the investigation the research was structured into two phases. The first phase of the research focused on identifying whether SMEs develop and use strategic performance measures. A survey of eight SMEs, in the south west of England, was undertaken using semi-structured interviews. The second phase involved a more in-depth study and was based on observing the introduction of a strategic performance measurement system in a small company. The results gained to date indicate that SMEs have a good understanding of financial measurement, and are moving towards customer focused measures. However, these measures typically lack strategic alignment and many may be questioned in regard of their value for business improvement. The observations made during phase two of the research, the development of a new strategic performance measurement system in an SME, indicated the potential planning and control benefits from the design process that was utilised. However, particular difficulties were evident in the development and implementation of the
\end{abstract}


performance measurement system. Further research (phase three) is now being undertaken to analyse these difficulties. This paper describes the first two phases of the work. An introduction is provided which establishes both the relationship of this work to existing literature and the context for the study. The key findings from the work are shown following a description of the research methodology that was employed. The paper concludes by summarising the key findings and by presenting a set of propositions that will be used to extend the research into phase three.

\section{Keywords}

Strategic Performance Measures, SMEs, Performance Measurement System Design, Forward Planning.

\section{INTRODUCTION}

This paper describes the initial findings of a three year, collaborative research project into Performance Measurement in SMEs. The aim of this stage of the research has been to identify whether the introduction of a strategic performance measurement system can improve planning and control in SMEs.

The advantages of redesigning traditional performance measurement systems to align them with business strategy have been well documented in the literature (Eccles, 1991; Ghalayini and Noble, 1996). Various frameworks and tools have been developed to facilitate the achievement of a balanced and strategically aligned performance measurement system (Lynch and Cross, 1991; Kaplan and Norton, 1992; Lochamy and Cox, 1994; Neely et al, 1996). However, much of the work that has been undertaken in this area has focused on larger companies. Previous research (Greatbanks and Boaden, 1998) suggests that although a large proportion of British business is made up of SMEs, few measure performance strategically. Therefore, a gap currently exists in this area and to develop it, empirical research is required.

One of the criticisms that has been levelled at many of the strategic performance measurement frameworks is that, while they address strategic issues, they do not explicitly link the strategic dimension with the operational dimension, making successful implementation unlikely (Ghalayini et al, 1997). However, Neely et al (1996) have developed a process for the design of a strategic performance measurement system which addresses this strategic/operational linkage through a two-phased approach. Phase One of this approach is focused on developing strategic measures with Phase Two addressing the development of operational measures to action the strategic measures. Although this methodology was developed in large companies it has now been applied in SMEs, but with limited success. An analysis of the case data resulting from the application of the methodology in SMEs has shown that although the design phase of the process was well received by the companies, few managed to implement the new system effectively (Bourne and Neely, 1998). To extend this work further and to investigate whether the introduction of a strategic performance measurement 
system can improve planning and control in SMEs, the following questions were formulated:

Do SMEs measure performance strategically?

What are the benefits of strategic performance measurement for SMEs?

Can the Neely et al (1996) methodology for designing performance measures be developed for use in SMEs?

\section{RESEARCH METHODOLOGY}

To effectively address these questions two complimentary research phases were designed.. The first phase was developed to address question 1 and aimed to gain a broad understanding of the way SMEs currently use performance measures. The second phase predominantly focused on questions 2 and 3, and attempted to obtain some depth of research through a field study. This field study involved observing the practical application of the Neely et al methodology in an SME.

Phase 1 of the research involved semi-structured interviews with managers from 8 SMEs. Due to the scarcity of strategic planning in the majority of SMEs, which is well documented (Mintzberg et al 1998, Cagliano et al 1998, Barnes et al 1999), it was decided to sample companies who had recently undertaken strategic improvement programmes. An additional rationale for this approach was to identify whether these companies, who may be termed exemplars as far as the specific domain is concerned, actually used performance measurement to help achieve their strategic objectives. To ensure consistency in the sample, all the companies were based in Devon and Cornwall and were primarily manufacturing focused. Their sizes ranged from $12-240$ employees with an average company size of 65 employees.

The interviews were designed to investigate the following broad areas:

- current performance measures;

- performance measure development;

- perceptions of performance measures;

- change management issues.

These areas were chosen to find out what performance measures the company was currently using; whether they were developed strategically, how useful they are perceived to be, and what issues would arise if the company were to change the system. Each interview was taped and subsequently transcribed. Summaries of the transcripts were then produced and were verified by the original interviewees. Triangulation was used to validate the summaries by showing them other managers in the company.

The second phase of the research involved a more in-depth field study which focused on the design of a strategic performance measurement system using the Neely et al (1996) methodology. This phase was designed to help identify the areas where SMEs might experience difficulties with the methodology. In addition to addressing question 1 , it was hoped that this study would provide an answer to 
question 2 , by demonstrating whether there is any benefit in terms of improved planning and control in introducing a strategic performance measurement system.

The field study was undertaken in a manufacturing SME based in Devon, with 54 employees. This was to ensure consistency with the sample that participated in Phase 1 . The study was carried out over approximately 6 months and focused on the observation of a series of facilitated workshops involving all the senior managers of the SME. In total five workshops were undertaken, the first three workshops were aimed at developing a set of strategic objectives for the company, with the latter two workshops focused on developing a performance measure for each objective. Interviews with each manager who was involved in the process were also carried out to identify individual commitment to the project, and the perceived importance of having a strategic performance measurement system.

The inductive nature of both the interviews and the field study advocated analysis using a grounded theory approach (Glaser and Strauss 1967). The codes and categories developed from each set of data were reviewed with a view to integrating similar incidents and properties, and a number of propositions were developed from the final data sets.

\section{$3 \quad$ FINDINGS}

Three themes emerged from the semi-structured interviews: current useful performance measures; performance measure development; and change management (See table 1). These themes were developed by integrating the categories from the original coding. The main findings were that although all the companies had a plethora of financial measures, which made up the majority of the formal measures used, these were not seen as being directly relevant to the day-today running of the business. However, many of the non-financial measures, or measures which had been developed informally by line managers, were invaluable in helping operations run smoothly.

Table 1

\begin{tabular}{ll}
\hline Themes & Main Characteristics \\
\hline $\begin{array}{l}\text { Current useful perform- } \\
\text { ance measures }\end{array}$ & $\begin{array}{l}\text { some formal and financial measures } \\
\text { many informal and non-financial measures } \\
\text { timely and relevant to running the business }\end{array}$ \\
$\begin{array}{l}\text { Performance measure } \\
\text { development }\end{array}$ & $\begin{array}{l}\text { post-problem (to prevent recurrence) } \\
\text { historical } \\
\text { responding to external pressures (customer/legislation) } \\
\text { ad hoc cost reduction }\end{array}$ \\
& Consultant led but internally championed
\end{tabular}


Full staff backing for change

Demonstrable benefits of change

In addition, many of the measures were customer oriented and had been developed in direct response to problems that affected the customers. Hence the measures that were perceived as being most useful included lead times; dispatch reliability, ontime delivery and product quality. The only financial measure which was perceived as being useful from an operational perspective was product cost analysis, which could be used to reduce production costs and offer more competitive quotes to customers.

None of the companies in the sample had attempted to develop their measures strategically. Instead, many measures were simply historical ('we have always measured this'), or were imposed either by legislation or customer requirements. The main reason for the introduction of new measures was to address problems that had occurred which, with hindsight, measurement could have prevented. Measures developed in this way were viewed as being the most useful, even though many were informal.

It was agreed that there was room for improvement in the current systems for measuring performance. The main reason given for this was the fact that many of the measures currently in use provided data that was out of date by the time it had been collated, and was therefore providing irrelevant information. When the managers were asked how they might approach this, the consensus was that successful change has to be well thought out and usually consultant led, due to the limited resources available internally. However, it was agreed that change initiatives would fail unless they were championed internally and received full commitment from all of the employees. In addition, to ensure this continued commitment, it was also deemed necessary for change to bring about demonstrable benefits.

The two major themes that were analysed in the second phase of the research were process issues and benefits of introducing the new system. The main findings were that the company commitment to the project hinged heavily on the Operations Manager. Without the Operations Manager's enthusiasm and commitment the completion of the process was doubtful. The facilitator had proposed that only the first section of the process, which aimed to develop the strategic level performance measures, should be completed through the workshops. This was because it was felt that Section Two of the methodology could only be achieved once these measures had been implemented and were being used effectively. However, the company struggled to complete the first section, and it seems unlikely that this will be completed.

The workshops themselves were very successful. All the managers found the identification of a set of strategic objectives a valuable exercise but most struggled when they came to developing the actual performance measures for those objectives. This seemed to be because each manager was assigned a set of objectives for which to develop measures individually, but because of the day-to- 
day issues of running the business, little preparatory thought was given to this exercise.

Despite the difficulties in completing the process, there were benefits gained from the development of the new system. The process of analysing the company and identifying the strategic objectives were acknowledged by the participants to have fostered consensus and focused their efforts. The process was also seen as valuable because it identified an effective method for controlling and supporting business planning through the use of critical measures to realise strategy.

\section{CONCLUSION}

The literature advocates that strategic performance measurement systems are the key to controlling successful business development. However, from this research it is clear that SMEs do not currently use performance measurement to achieve their strategic objectives. From the results of the interviews, several propositions have been developed to explain this:

- SMEs introduce performance measures only through necessity - i.e. for financial reports; government legislation; customer requirements; or to prevent problem recurrence.

- SMEs have a range of performance measures, but many of these are irrelevant.

- Key operational measures are often developed informally and are minimal, but very useful.

- Successful change requires time and effort from the management, which is difficult to maintain.

These propositions attempt to explain why, excluding the smallest company where it was felt that total control had been established, all of the companies expressed a desire to improve their performance measurement systems. However, even though a methodology was used that had been proven in large companies, the observations obtained from the field study indicated that the application of the methodology in SMEs was problematic.

This research has demonstrated that although it is not current practice, designing a strategically based performance measurement system is useful for SMEs, because it enables them to explicitly state the company objectives and facilitates the identification of both problem areas and growth potential. This overview enables the development of performance measures which have the potential to drive the business forward. However, the time and commitment required to develop this new system proved difficult to maintain in the study, making it unlikely that the process will move from the development of strategic measures to those which will link the strategy to operations. At this stage therefore, it cannot be concluded that strategic performance measurement improves planning and control in SMEs. There is a need for more research in this area to identify the specific characteristics and that are required to develop this existing methodology (Neely et al 1996) for successful application in SMEs. 


\section{REFERENCES}

Barnes, D. Gill, R. Mills, J. O'Brien, T, and Rowbotham, F. (1999)

Proceedings of the Second International SMESME Conference - Stimulating Manufacturing Excellence in Small and Medium Sized Enterprises, Plymouth, $\mathrm{UK}, \mathrm{pp} 135-142$.

Bourne, M. and Neely, A. (1998) Why do Performance Measurement Initiatives Succeed and Fail? Proceedings of the $1^{\text {st }}$ International Conference on Performance Measurement - Theory and Practice, Cambridge, UK, pp165-173.

Cagliano, R. Spina, G. Verganti, R. and Zotteri, G. (1998) Designing BPR

Support Services for Small Firms, International Journal of Operations and Production Management, Vol 18, No 9/10, pp865-885.

Eccles R. (1991) The Performance Measurement Manifesto. Harvard

Business Review, Jan-Feb, 131-137.

Ghalayini, A. and Noble, J. (1996) The Changing Basis of Performance

Measurement. International Journal of Operations and Production Management, Vol 16, No 8, 63-80.

Ghalayini, A. Noble, J. and Crowe, T. (1997) An Integrated Dynamic

Performance Measurement System for Improving Manufacturing Competitiveness, International Journal of Production Economics, Vol 48, pp207-225.

Glaser, B. and Strauss, A. (1967) The Discovery of Grounded Theory:

Strategies for Qualitative Research. Aldine Publishing Co. Publications, New York.

Greatbanks, R. and Boaden, R. (1998) Can SMMEs Afford to Measure

Performance? Proceedings of the $1^{\text {st }}$ International Conference on Performance Measurement - Theory and Practice, Cambridge, UK, pp117-124.

Kaplan, R. and Norton, D. (1992) The Balanced Scorecard: The Measures

that Drive Performance. Harvard Business Review, Jan-Feb, 71-79.

Lochamy III, A. and Cox, F. (1994) Reengineering Performance

Measurement. Irwin Professional Publishing, New York.

Lynch, R. and Cross, K. (1991) Measure Up! Yardsticks for Continuous

Improvement. Blackwell, Oxford.

Mintzberg, H. Quinn, J. and Ghoshal, S. (1998) The Strategy Process.

Prentice Hall, London.

Neely, A. Mills, J. Gregory, M. Richards, H. Platts, K. and Bourne, M.

(1996) Getting The Measure of Your Business, Works Management, Cambridge. 